\title{
Analysis of Physical, Mechanical and Thermal Degradation of Gelatin-Based Film-Exploring the Biopolymer for Plastic Advancement
}

\author{
Asia Neelam¹, Omm-e-Hany¹, Shagufta Ishteyaq², Kekshan Nawaz², Syed Junaid Mahmood ${ }^{3}$, Mohammad \\ Siddique $^{4}$
}

${ }^{1}$ Institute of Environmental Studies, University of Karachi, Pakistan, ${ }^{2}$ Department of Chemical Engineering, University of Karachi, Pakistan, ${ }^{3}$ Pakistan Council of Scientific and Industrial Research (PCSIR), Karachi, Pakistan, ${ }^{4}$ Department of Chemical Engineering, Faculty of Engineering and Architecture, Balochistan University of Information Technology, Engineering and Management Sciences Quetta, Pakistan

\begin{abstract}
Gelatin is an important natural biopolymer protein extracted from fibrous insoluble collagen and broadly used by various industries because of its stabilizing, and easy handling usage. Nowadays, scientists are interested to find out the alternative polymer of plastic, provide food safety as well having the properties of rapid degradation and environmental friendly. In this study, an investigation was carried out to figure out the property of gelatin as a bioplastic polymer. Gelatin based biofilms are produce in laboratory by solution casting method in Petri plates. The prepared biofilms characterized by tensile strength, break point elongation, swelling behavior, thermogravimetric analysis and degradation. Kinetic studies of pyrolysis of gelatin was investigated by using Friedman method and integral method apparent activation energy (E) were evaluated at constant heating rate. Food coating test were also employed to analysis the gelatin coating protection on food materials.
\end{abstract}

Key words: Polymer; Gelatin; Tensile Strength; Thermogravimetric Analysis; Degradation

Corresponding author's email: shaguftai@uok.edu.pk

\section{INTRODUCTION}

There is an alarming situation of environment because of petro-based plastic which enormously effect our planet Due to its persist, xenobiotic nature, disposal and production of toxic dioxin, vinyl, and polystyrene during the incineration of plastic wastes (Han et al., 2015; Barnes et al., 2009; Alvarez-Barrag et al., 2016). Along with these problem $\mathrm{Co} 2$ emission from plastic manufacturing industries were expediently increase from 1971-2004,which contributing in the global warming (Nordell, 2003). Approximately 6\% of the whole oil supply of the world is used in the production of plastics and its packing products (Zawya, 2011). Plastic utensils releases carcinogenic or hormonal disruption chemicals (bisphenol-A) upon heating and mixed with food (Mcrandle, 2004). Low density polyethylene (LDPE) is contribute as a major cause of environmental pollution due to its recalcitrant nature and characterized as a non-biodegradable thermoplastic until they fragmented into low molecular weight that can easily assimilated by microorganism (Francis et al., 2010). Sometime their figments produce toxic monomers that's links to the cancer and reproductive problems, hence interest is rapid demand to develop the material which don't burden the environment.

Now people are more aware about the harmful effects of petrochemical derived plastic materials in the environment now they are switching towards the ecofriendly solution. which can be disposed in environment and can easily degrade through the enzymatic actions of microorganisms follow a ful equation of mineralization i.e water, CO2 biomass, humic matter and various other natural (Azios, 2007). This is also called as a genuine biodegradable plastic, due to the absence of any toxic by product.

Today, Thedevelopment of biodegradable food packaging has been a subject of interest over the years (Shah et al., 2008; Iwata, 2015). Bioplastic is not as new as we know, in the late 80s scientist of Massachusetts Institute of Technology isolate the novel enzyme 'thiolase' which performs the key role in the biological production of bioplastic followed by the discovery of the genes required for the synthesis than in the 1987 first patent application of bioplastic were made which is accepted in 1993 (DiGregorio, 2009). Along many natural sources of bioplastic, Gelatin has many application benefits on film manufacturing including good film-forming, well gas and oil resistance, low price, nontoxicity, and ultimately biodegradable 
Analysis of Physical, Mechanical and Thermal Degradation of Gelatin-Based

Film-Exploring the Biopolymerfor Plastic Advancement

properties. It is a promising candidate in the bioplastic manufacturing field for food and drug packaging (Patil et al., 2000).

\section{MATERIALS AND METHODS Preparation of film}

In the preparation of film Gelatin powder were purchased from supplier (Merk) and glycerin 99\% purity (food grade), 12 grams of gelatin powder dissolved in $80 \mathrm{ml}$ of hot water, fortified with $3 \mathrm{ml}$ of glycerin as plasticizer. Heat the mixture till it becomes clear and thick.Stirr spatula continuously to avoid lumps in the solution. After 15 mints pour the mixture into the Petri plates and let it dry for 24 Hours.

\section{Mechanical Testing}

Mechanical properties of prepared Biofilm including tensile strength and elongation at breakpoints were analyzed at room temperature as per ASTM D412 standard using universal testing machine (Model Instron UTM-4301) at cross head separation rate $10 \mathrm{~mm} / \mathrm{min}$. Recorded values of tensile strength and elongation is the average of three measurement.

\section{Swelling Index}

The water sorption capacity of film investigated by Gravimetric method, at room temperature $\left(23 \pm 2{ }^{\circ} \mathrm{C}\right)$ pre-weighted sample of biofilm was soaked with deionized water for required time, drawn the sample and dried on filter paper and then reweight. The swelling percentage was calculated using the formula.

$$
\text { Swelling index percentage }=\frac{\mathrm{W} \alpha-\mathrm{W} \Omega}{\mathrm{W} \Omega} \times 100
$$

Where Wa is a weight of sample after soaking and $W \Omega$ represents the initial weight of sample respectively, This method was adapted from (González and Alvarez Igarzabal, 2013).

\section{Biodegradation Test}

The biodegradation behavior of gelatin carried out by ascertains the loss in weight during the soil burial test. Garden soiland coastal area $(1200 \mathrm{~g})$ soil was taken in different pots. A weighed amount $(1 \mathrm{~g})$ of each of the samples that is, Gelatin and LDPE (as control) was buried in the pots such that the soil covered the polymer from all the sides. The pots were kept at ambient condition and amended with mineral salt media. The film was taken out from the soil, washed and dries to check for any weight loss.

\section{Weight loss Measurement}

The Films after soil burial test were analyzed by gravimetrically through weight loss calculation.

$$
\text { Weight loss percentage }=\frac{\mathrm{Wi}-\mathrm{Wf}}{\mathrm{Wi}} \times 100
$$

Where Wi the initial weight of the film sample and Wf isthe treated weight of the film after exposed to the soil.

$$
\text { Rate /day }=\frac{\text { Weight loss percentage }}{\text { number of days }}
$$

\section{Uv barrier Property}

Uv barrier property of gelatin biofilm were testing using the simple protocol. A pre culture Bacillus subtilis petriplate (9cm in diameter) were half covered with gelatin film were exposed to Uv light ( $252 \mathrm{~nm}$ ) for 15 mins and 25 mins, than petri plates were incubated at $35^{\circ} \mathrm{C}$ for 24 hours. Tests were performed in triples. Fruit Coating

Apple fruits (Malus domestica var. Anna) were purchased from local market of Karachi, Pakistan. Fruit sample were sorted for equal size and without defect.Then, they were washed with $20 \%$ Acetic acid to remove commercial coating and sanitized by $250 \mathrm{ppm}$ sodium hypochlorite solution for 2 min.Samples were washed thoroughly with distilled water, air dried and then coated with Gelatin solution. Experiment were done in replicates and store in ambient condition. Moisture content of samples were monitored periodically according to the design protocol. All the experiment was repeated thrice and standard deviation were calibrated.

\section{Thermogravimetric Procedure}

Thermogravimetric analysis (TGA) was performed using TA instrument (TGA/ SDTA 851 Mettler Telodo).TGA analyzer was used to measure and record the sample mass change with temperature during the thermal 
degradation reaction. During this study TGA providing with gas controller (TS0800) with nitrogen gas purging rate would $65 \mathrm{ml} / \mathrm{min}$ throughout experiment. The temperature rate was set around $300-800 \mathrm{~K}$ with the temperature increasing rate $30{ }^{\circ} \mathrm{C} / \mathrm{min}$.

\section{Theoretical consideration}

The most common differential is conversional method is that of Friedman. It is the most straightforward way to evaluate the effective activation energy (Ea).This method is a differential is conversional method, and it directly based on following equations

$$
\beta \frac{d x}{d T}=A \exp \left(-\frac{E}{R T}\right) f(x)
$$

Where A, Rand $E$ is the pre-exponential factor, gas contact and activation energy successfully drive by the Arrhenius equation, given by

$$
\begin{aligned}
& \mathrm{K}(\mathrm{T})=\mathrm{A} \exp \left(-\frac{E}{R T}\right) \\
& \mathrm{X}=\frac{\mathrm{w} 0-\mathrm{Wt}}{\mathrm{wo}-\mathrm{W} \Omega} \ldots \ldots \ldots \ldots \ldots
\end{aligned}
$$

From the logarithm of equation (a) it is easy to obtain values for $E$ over a wide range of conversions by plotting $\beta \frac{d x}{d T}$ against $1 / T$ for a constant $\mathrm{x}$ value.

$$
\ln \left(\frac{d x}{d t}\right)=\ln \beta \frac{d x}{d T}=\ln \left[A f(x)-\frac{E}{R T}\right]
$$

$\mathrm{K}(\mathrm{T})$ the temperature dependence of the rate of weight loss $(\mathrm{x})$. Wo is the intial weight $(\mathrm{mg})$, wt weight after time "t" minutes and is the weight after pyrolysis (mg) (Aboulkas et al., 2010; Friedman, 1964).

Another way to calculate the activation energy is by using weight loss data for analysis of decomposition of kinetics of Gelatin. The extent of conversion of material pyrolyzed ' $x$ ' were define by equation 1.Than the rate of reaction can also be write as

$$
\begin{aligned}
\frac{d x}{d T}=K \quad(1-x) \ldots \ldots \ldots \ldots \ldots \ldots \ldots \ldots & \\
\mathrm{K} & =\mathrm{k}_{0} \exp \left(-\frac{E}{R T}\right)
\end{aligned}
$$

Where $\mathrm{R}$ is the universal gas constant, $\mathrm{E}$ is the activation energy and $\mathrm{k}_{0}$ is the pre exponential factor. The integration of Equation (2) result an Activation energy, which can easily be calculated by plotting a graph of $\ln [-\ln (1-x)]$ against 1/T (Kayacan and Dogan, 2008).

$$
\ln [-\ln (1-\mathrm{x})]=\left[\frac{\mathrm{k}_{\mathrm{o}} \mathrm{R} T^{2}}{a E}\left(1-\frac{2 R T}{E}\right]-\frac{E}{R T}\right]
$$

\section{RESULTS AND DISCUSSION}

The aim of this work was to evaluate the effectiveness to Gelatin as a biopolymer for synthesis of plastic. Biopolymers are widely used as packing materials because of their good degradability as they are typically extracted from natural origin. They can easily characterized as edible coating as they applied directly to the food surface by dipping, coating or spraying (Hanani et al., 2014). Gelatin, typically characterized as protein were coating on apply to enhance the shelf life, the freshness of apple remain up to 22 days during the study period at ambient condition. After 22 days of storage in ambient condition weight loss of apple (Malus domestica var. Anna) were found to be steadily decrease in control as compared to coated apples (Fig 1) 
Analysis of Physical, Mechanical and Thermal Degradation of Gelatin-Based Film-Exploring the Biopolymerfor Plastic Advancement

as the coated gelatin layer delayed the migration of moisture in the environment. Similarly waxes are also used as food coating to increase the shelf life but their mixing with artificial additives like thiabendazole is most harmful effect, reported to cause bladder cancer. However, Chitosan and Cellulose as a natural polymer for coating of fruits, bring environmentally safe and good film forming characters (List D 2005; Kalifa et al., 2016; Shao et al., 2012; Yang et al., 2014; Martinez et al., 2010). Incontast to these natural polymer, gelatin is protein whereas chitosan and wax are polysaccharides and lipid respectively. According to Cuq.B (1998) protein based films possess better properties than polysaccharide films. This protein based Gelatin film also incorporated with essential oil to increase its antimicrobial and antioxidant potential. Ahmad et al., (2012) prepared a gelatin film with essential oil of lemon grass to extend is properties and self-life during store period i.e. refrigeration.

The visible change were found in the degradation of gelatin film by soil burial test (Table 1). In Garden soil $80 \%$ degradation rate were calculated in 5 days whereas in Coastal soil $70 \%$ estimated. The days rate of degradation is approximate calculated as $16 \%$ and $14 \%$ respectively. However in the same experimental condition no weight loss was observed in LDPE samples during 5 days. In contrast to the petroleum based plastic, bioplastic can be easily biodegradable with no environmental demage.In assessment of soil burial test the surface of plastic or bioplastic acts as a carbon and nitrogen source for microorganism growth, Therefore microorganism consume it as food and increase their biomass, However microbial development depends on the constitute and the nature of polymer (Lucas et al., 2008). Our result indicates no net change in LDPE weight as it contain long carbon chain which is hydrophobic in nature makes them microbial resistant, It is estimated that under normal condition polymer takes more than 10 decades for its complete mineralization (Gajendiran et al., 2016; Ohtake et al., 1998; Contat-Rodrigo and Greus, 2002). According to Roy et al., (2007) polyethylene degrade $0.5 \%$ in 100 years and with exposed to sunlight for 2 years its degradation is around $1 \%$. According to the Maheshwari et al., 2013) Biodegradable plastic have many advantages as it has non-toxic end product, much safer for consumer point of view, consume less than $65 \%$ energy than production of conventional plastic. Howeverthere is lot of room for improvement is present in Bioplastic.

For the approach of swelling behavior of films were emerged in water to verify the effect and analysis the hydrophilic nature of gelatin based films. Water diffuses into the network chains of the films, thus, causing the film to swell. The swelling of the films were rapid during the initial hours and later followed by slower swelling rate until the film was fragmented into smaller pieces. Wang et al., (2008) gelatin material tends to swell or dissolve in high moisture content due to its high hydroscopic nature. Therefore composite film will be recommended with combination to polysaccharide and other natural and synthesis material for film manufacturing.

Thermogravimetric analysis (TGA) of the experimental sample is based on weight vs temperature. This techniques mostly used for kinetic analysis of devolatilization process, shows the behaviors of polymer. They show server changes upon heating and release gases and liquids with a change in their shape, color and molecular weight (Mohammed, 1993). Here the mass of the polymer is measure as function of temperature and time. At ambient and $300{ }^{\circ} \mathrm{C}$ mostly moisture, residual solvent, additives and oligomers generally evaporate. Amino resins, Volatile degradation products generally required temperature above $200 \mathrm{C}$. When the Gelatin plastic began to decompose at high temperatures, the thermogram show a drop in the curve indicating a loss of mass at high temperature. The degradation temperature of gelatin is around $340 \circ \mathrm{C}$. The weight of the sample decreases as the temperature of TGA increase (fig 3). Initially at low temperature T $\left(<150{ }^{\circ} \mathrm{C}\right)$ compounds having low molecular weight like water decomposed first, temperature between $\left(150-250^{\circ} \mathrm{C}\right.$ ) additives decomposed. At the temperature of $250-500$ or more thermal (inert gas) or thermo oxidative decomposition occur. The pyrolysis of gelatin by thermogravimetry revealed the decomposition in three stages: water evaporation, active and passive pyrolysis and the decomposition. As we can see from figure 3 , the devolatization occurs at about $450 \mathrm{~K}$ and the process continuously increase with the loss of weight until the temperature reaches about $750 \mathrm{~K}$. The apparent value of activation energy is about $20 \mathrm{KJ} / \mathrm{mol}$ from the Friedman method Fig 5 and the method of integral present by (Kayancan and Dogan, 2008) gives approximately $17 \mathrm{KJ} / \mathrm{mol}$ activation energy Fig 6 . Both the methods shows reasonable fitting of data to the straight line provide around same amount of activation energy at the same heating rate. 
Analysis of Physical, Mechanical and Thermal Degradation of Gelatin-Based

Film-Exploring the Biopolymerfor Plastic Advancement

Table 1: Weight loss of plastic after 5 days of study period with comparison of Garden and Coastal soil

\begin{tabular}{|l|c|c|}
\hline Samples & Garden Soil & Coastal soil \\
\hline Gelatin film & $0.2 \mathrm{~g}$ & 0.3 \\
\hline LDPE & $1 \mathrm{~g}$ & $1 \mathrm{~g}$ \\
\hline
\end{tabular}

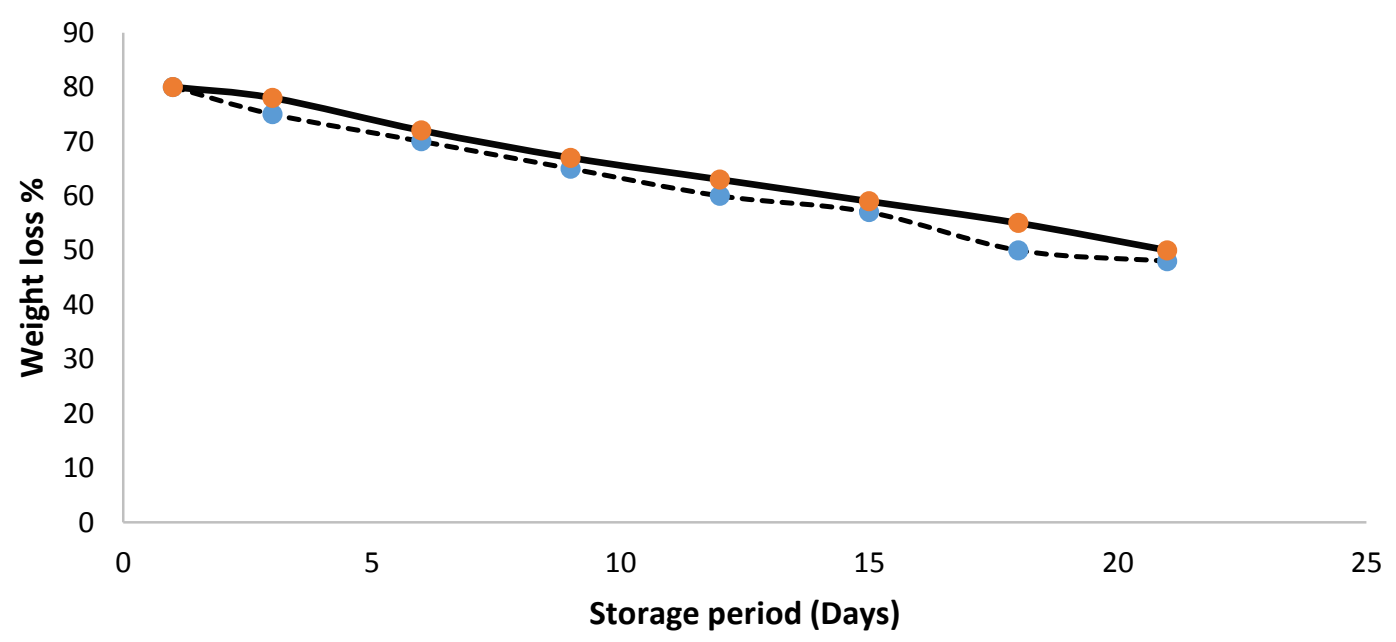

Figure 1: Effect of Gelatin coating solution and uncoated on weight loss of Apple fruit at ambient condition

Table 2: Comparison of Ultraviolent radiation on gelation and plastic film on different exposure time

\begin{tabular}{|l|c|c|c|}
\hline Samples & $\begin{array}{c}\text { Exposure Time } \\
\text { (5 minutes) }\end{array}$ & $\begin{array}{c}\text { Exposure Time } \\
\text { (15 minutes) }\end{array}$ & $\begin{array}{c}\text { Exposure Time } \\
\text { (25 minutes) }\end{array}$ \\
\hline Gelatin film & +++ & +++ & +++ \\
\hline LDPE & --- & --- & +-- \\
\hline Control & --- & -- & --- \\
\hline
\end{tabular}

Key $=+++$ Growth observed, --- = No growth observed, $+--=$ few colonies observed 


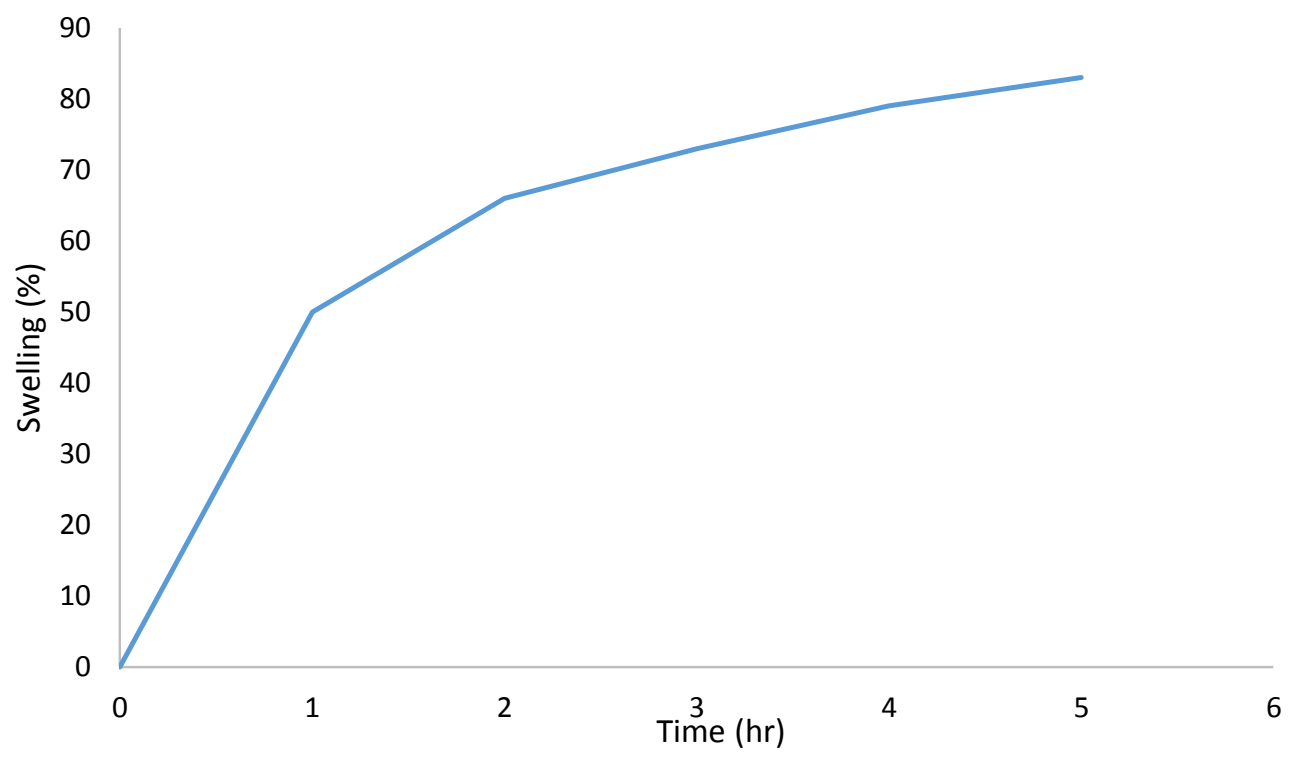

Figure 2: Graphical representation of swelling property of gelatin film

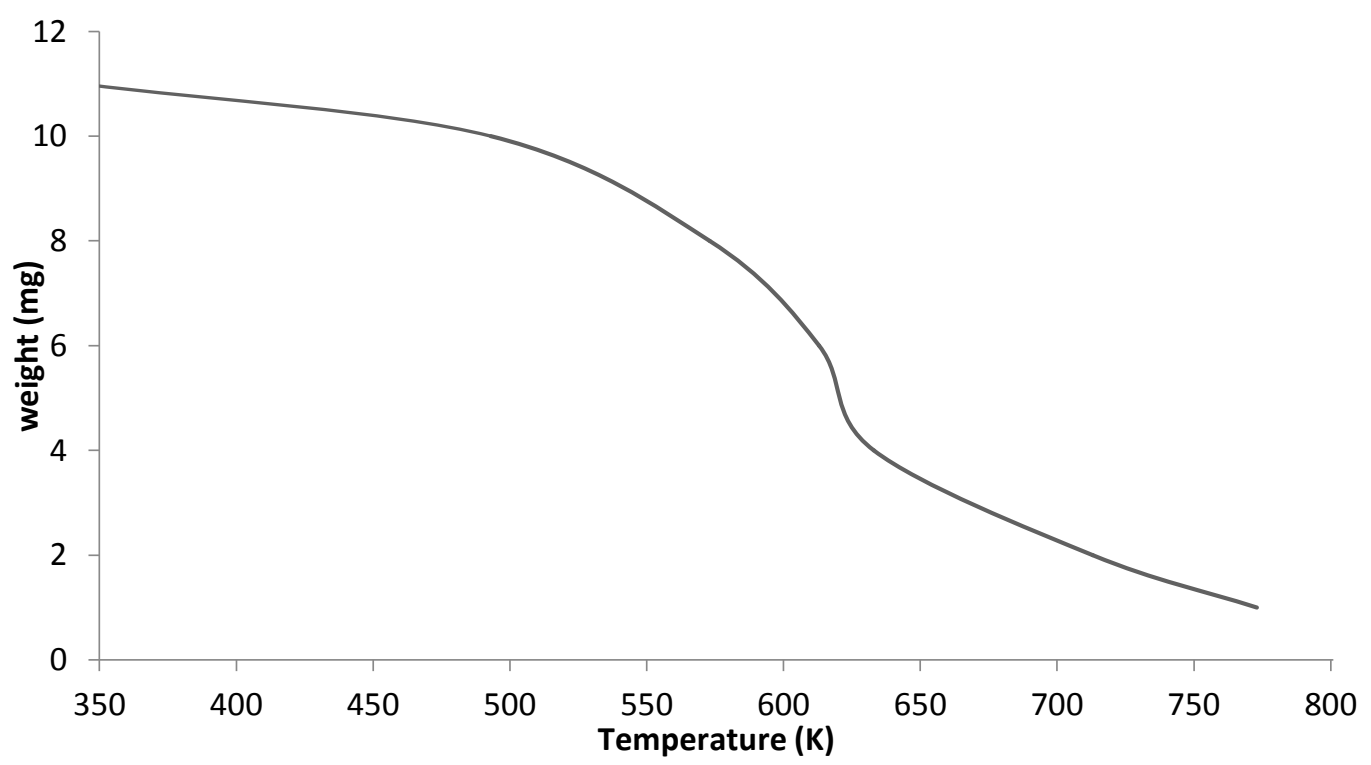

Figure 3: TGA curve of gelatin shows the relationship of weight and temperature 
Analysis of Physical, Mechanical and Thermal Degradation of Gelatin-Based

Film-Exploring the Biopolymerfor Plastic Advancement

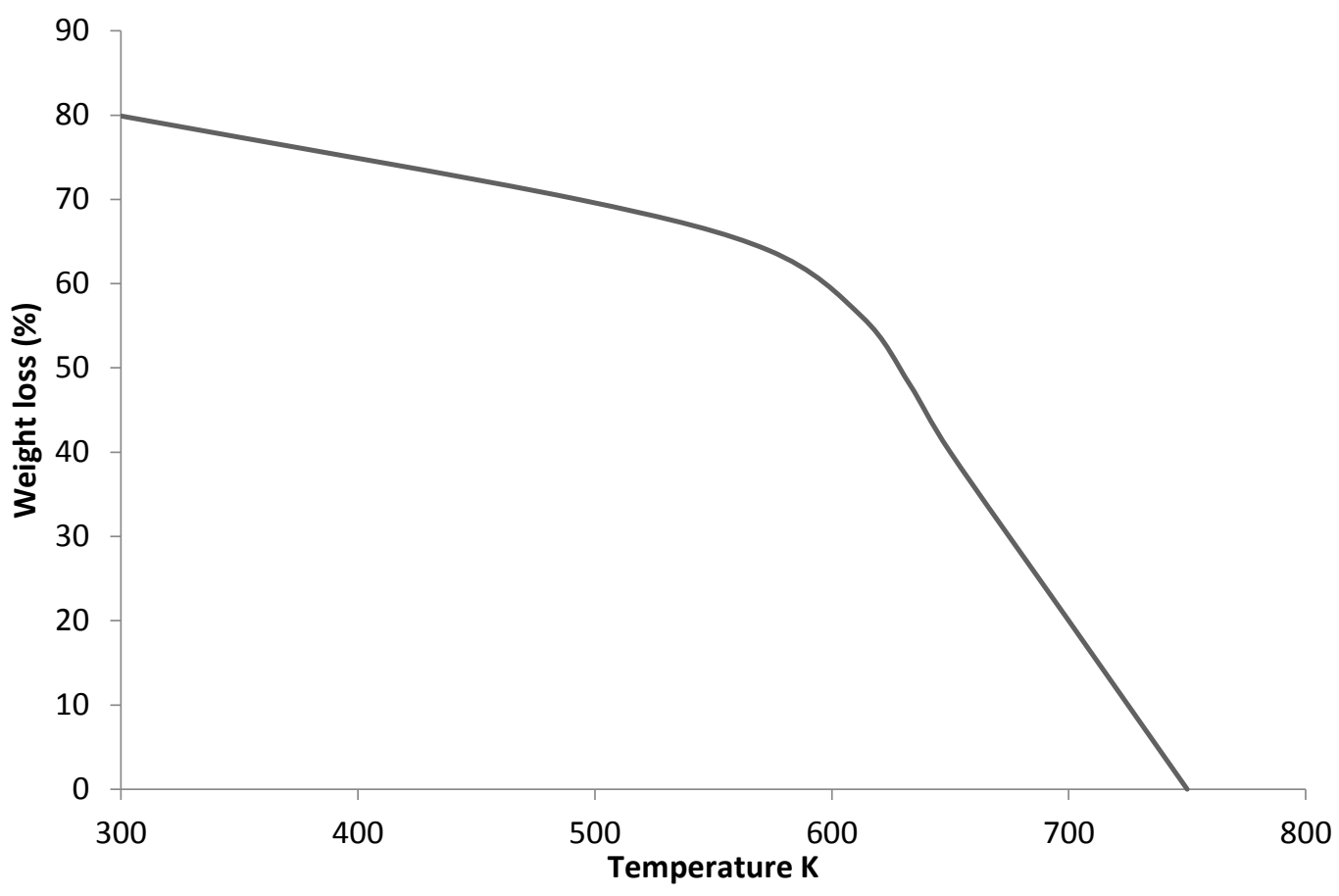

Figure 4: Mass loss versus temperature curve of TGA at heating rate $5 \mathrm{~K} / \mathrm{min}$

Table 3: Physical process of gelatin film with comparison of LDPE.

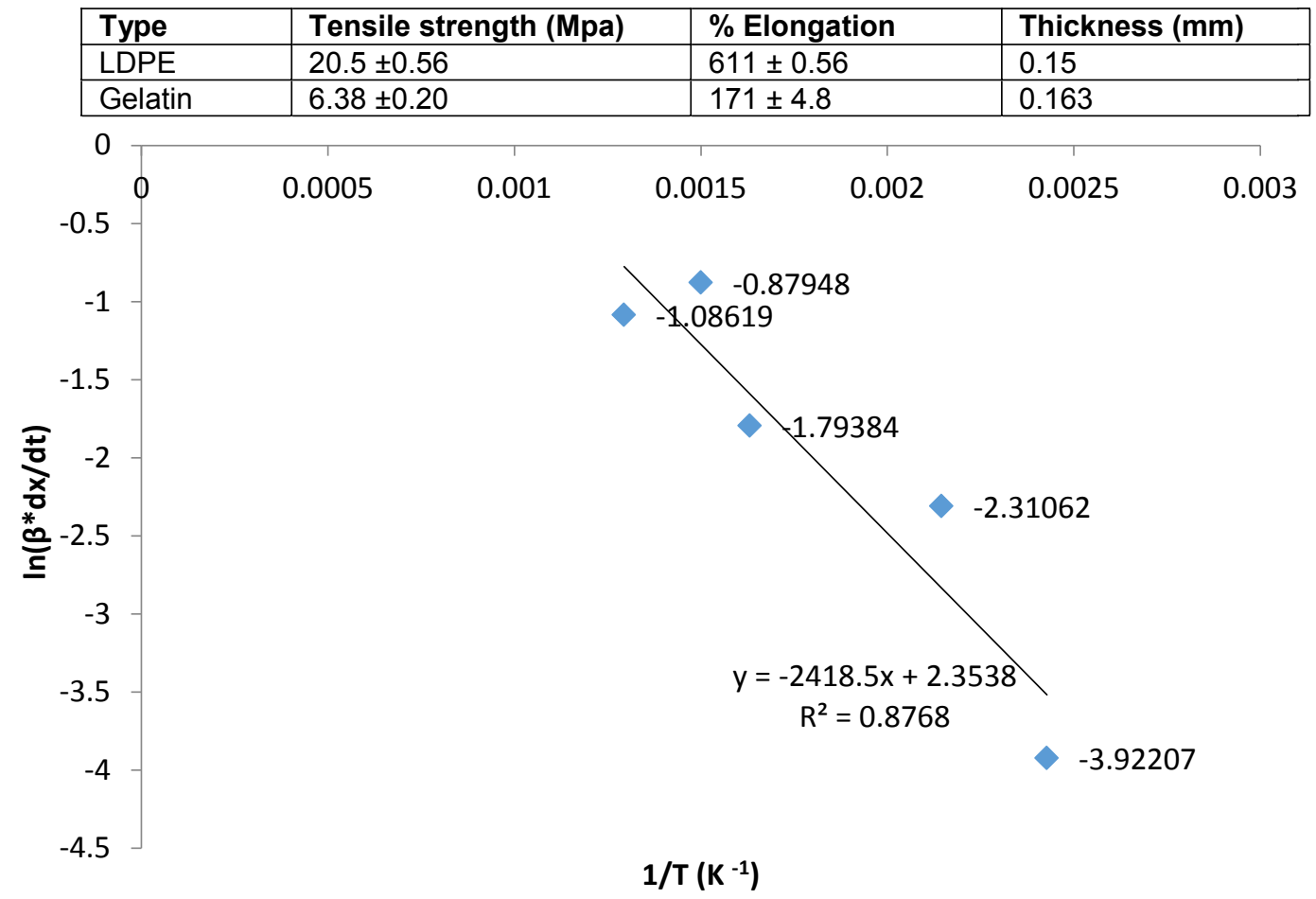

Figure 5: $\ln \left(\beta^{*} d x / d t\right)$ as a function of $1 / T$ for the pyrolysis reaction of Gelatin film by friedman method 
Analysis of Physical, Mechanical and Thermal Degradation of Gelatin-Based

Film-Exploring the Biopolymerfor Plastic Advancement

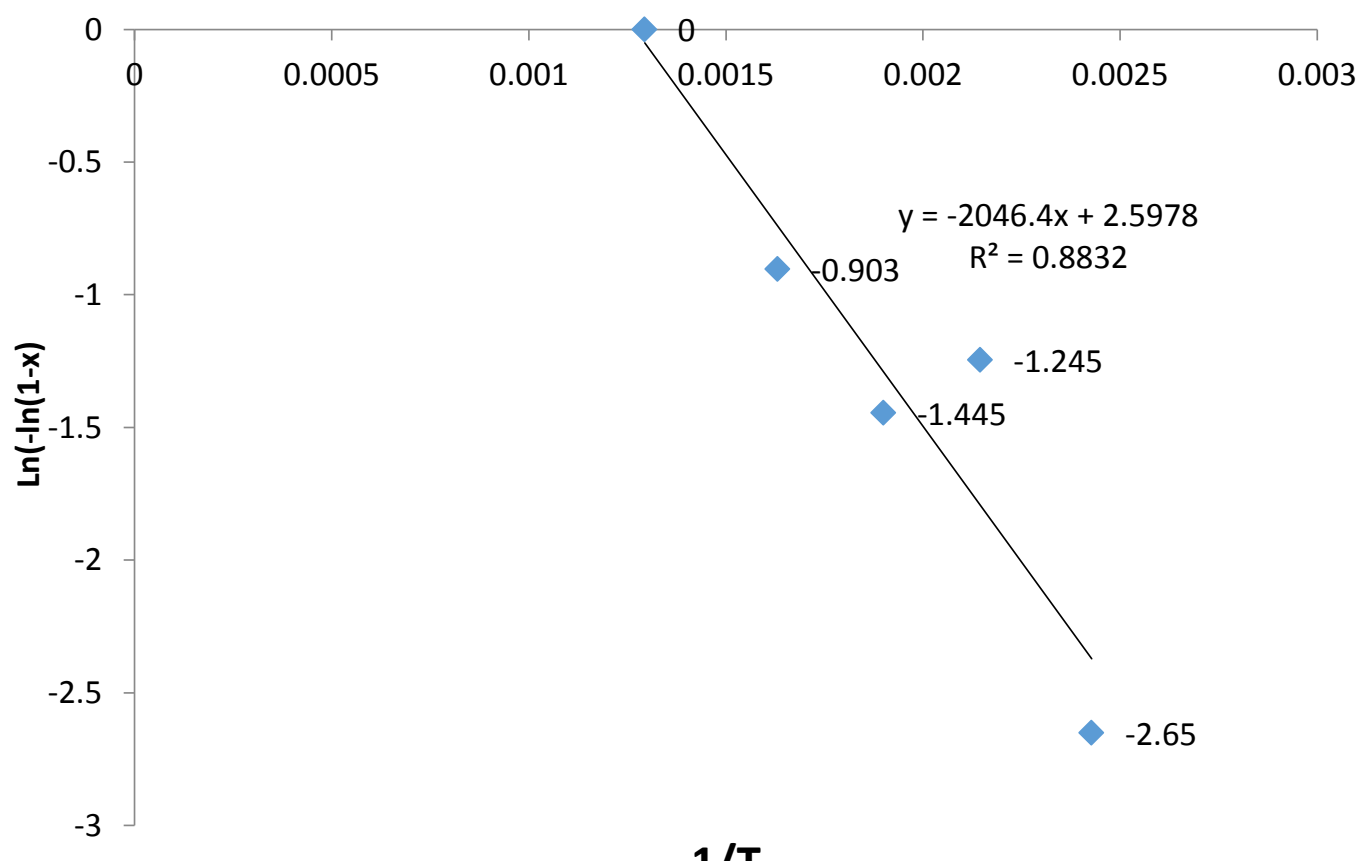

Figure 6: $\operatorname{Ln}(-\ln (1-x)$ as a function of $1 / T$ for the pyrolysis reaction of Gelatin film

\section{CONCLUSION}

In conclusion, this study showed that gelation can be utilized as a promising biopolymer in the plastic advancement. As solo compound it is very week in tensile strength and bearing a property of hydrophilic nature but having a high ability of degradation make it applicable in synthesis of plastic but for the point of strength it is recommended to use it by mixing a certain amount of synthesis and gelatin polymer, so it may meet all the performance requirement on packing industries. As the Biopolymer industries have a positive future all the sectors now required biodegradable and environmentally friendly polymer due to its environmental benefits.

\section{REFERENCES}

- Ahmed M, Benjakul S, Sumpavapol P, Nirmal Np. (2012). Quality changes of sea bass slices wrapped with gelatin film incorporated with lemongrass essential oil. Int $J$ food Microbiology 155(3):171-178.

- Azios T. (2007). A primer on biodegradable plastics. Christian Science Monitor. Retrieved from Academic One File database.

- Barnes DKA, Galgani F, Thompson RC, Barlaz M. (2009). Accumulation and fragmentation of plastic debris in global environments. Phil. Trans. R. Soc. 364:1985-1998.

- Contat-Rodrigo L, Ribes Greus A. (2002). Biodegradation studies on LDPE filled with biodegradable additives: morphological changes. Journal of Applied Polymer Science 83(8):1683-1691.

- Cuq B, Gontrad N, Guilbert S. (1998). Proteins as Agricultural Polymers for Packaging Production. Cereal Chemistry 75:1-9.

- DiGregorio BE. (2009). Biobased Performance Bioplastic: Mirel. Chemistry and Biology 16(1):1-2.

- Francis V, Raghul SS, Sarita GB, Eby TT. (2010). Microbial degradation studies on linear low-density poly(ethylene)-poly (vinyl alcohol) blends using Vibrio sp. International Conference on advances in 
Analysis of Physical, Mechanical and Thermal Degradation of Gelatin-Based Film-Exploring the Biopolymerfor Plastic Advancement

polymer Technology, pp 26-27.

- Gajendiran A, Krishnamoorthy S, Abraham J. (2016). Microbial degradation of low-density polyethylene (LDPE) by Aspergillus clavatus strain JASK1 isolated from landfill soil. 3 Biotech. 6(1):52

- Gielen D, Newman J, Patel MK. (2008). Reducing Industrial Energy Use and CO2 Emissions: The Role of Materials Science. Harnessing Materials for Energy 33:817-833.

- González A, Alvarez Igarzabal CI. (2013). Soy protein-Poly (lactic acid) bilayer films as biodegradable material for active food packaging. Food Hydrocoll 33(2):289-296.

- Han J, Shin SH, Park KM, Kim KM. (2015). Characterization of physical, mechanical, and antioxidant properties of soy proteinbased bioplastic films containing carboxymethylcellulose and catechin. Food Science and Biotechnology 24:939-945.

- Alvarez-Barragán J, Domínguez-Malfavón L, Vargas-Suárez M, Hern-andez R, Aguilar-Osorio G, Loza-Tavera H. (2016). Biodegradative activities of selected environmental fungi on a polyester polyurethane varnish and polyether polyurethane foams. Appl Environ Microbiol 82(17):5225-35.

- Iwata T. (2015). Biodegradable and bio-based polymers: future prospects of eco-friendly plastics. Angewandte Chemie-International Edition 54(11):3210-3215.

- Khalifa I, Barakat H, El-Mansy HA, Soliman SA. (2016). Enhancing the keeping quality of fresh strawberry using chitosanincorporated olive processing wastes. Food Biosci 13:69-75.

- List D. (2005). Reregistration eligibility decision for thidiazuron. Environ Prot 4:1-12.

- Lucas N, Bienaime C, Belloy C, Queneudec M, Silvestre F, Nava-Saucedo JE. (2008). Polymer biodegradation: Mechanisms and estimation techniques. Chemosphere 73(4):429-42.

- Lucasa N, Bienaime C, Belloy C, Queneudec M, Silvestred F, Saucedo JEN. (2008). Polymer biodegradation: Mechanisms and estimation techniques - A review. Chemosphere 73(4):429-442.

- Martínez-Camacho AP, Cortez-Rocha MO, Ezquerra-Brauer JM, Graciano-Verdugo AZ, RodriguezFe'lix F, Castillo-Ortega MM, et al.(2010) Chitosan composite films: thermal, structural, mechanical and antifungal properties. Carbohydr Polym 82:305-15.

- Mohammed AA. (1993). Plastics Chemistry, Library Printing and Publishing, University of Mosul, Iraq.

- Nordell B. (2003). Thermal Pollution Causes Global Warming. Global and Planetary Change 38:305-312.

- Ohtake Y, Kobayashi T, Asabe H, Murakami N. (1998). Studies on biodegradation of LDPE- observation of LDPE films scattered in agricultural fields or in garden soil. Polym Degrad Stab 60:79-84.

- Patil RD, Mark JE, Apostolov A, Vassileva E, Fakirov S. (2000). Crystallization of water in some crosslinked gelatins. European Polymer Journal 36:1055-1061.

- Shah AA, Hasan F, Hameed A, Ahmed S. (2008). Biological degradation of plastics: a comprehensive review. Biotechnology Advances 26:246-265.

- Shao XF, Tu K, Tu S, Tu J. (2012). A combination of heat treatment and chitosan coating delays ripening and reduces decay in "GALA" apple fruit. J Food Qual 35:83-92.

- Unmar G, Mohee R. (2008). Assessing the effect of biodegradable and degradable plastics on the composting of green wastes and compost quality. Bioresour Technol. 99(15):6738-6744.

- Yang G, Yue J, Gong X, Qian B, Wang H, Deng Y, et al. (2014). Blueberry leaf extracts incorporated chitosan coatings for preserving postharvest quality of fresh blueberries. Postharvest Biol Technol 92:46-53. 